\title{
THE USE OF ACTIVE THERMOVISION TO STUDY MULTI-LAYERED CERAMIC FORMS
}

\author{
Krzysztof ŻABA, Sandra PUCHLERSKA, Marcin ZYWERT \\ AGH - University of Science and Technology, Faculty of Non-Ferrous Metals, Cracow, Poland, EU, \\ krzyzaba@agh.edu.pl, spuchler@agh.edu.pl, marcinzywert@op.pl
}

https://doi.org/10.37904/metal.2019.799

\begin{abstract}
In precise casting, the important parameters of multi-layered ceramic forms are their thickness and porosity. Defects, e.g. in the form of cracks, are determined visually. However, the remaining defects of the molds are not revealed before liquid metal pouring, which means that many defects may occur in the castings. The only way to determine the quality of molds in their volume seems to be non-destructive testing. One of the investigations is active thermovision, which involves observing temperature changes of the excited object using an external heat source.

The paper presents the results of thermovision tests of a ceramic form with the use of various heat sources used for its heating. A research stand equipped with a FLIR thermal imaging camera, heater, radiators and a laboratory dryer was used for the research. The results were developed using the dedicated FLIR Reaserch IR software. The presented results in the form of thermograms show the temperature differences of individual mold elements, which may indicate their differences in thickness and porosity. Thermovision can thus be used to eliminate defective forms from further stages of production, which translates into lower costs and higher quality of products.
\end{abstract}

Keywords: Active thermovision, aviation industry, NDT applications

\section{INTRODUCTION}

Thermovision is a dynamically developing field with broad applications, mainly in industry, medicine and energy. In recent years, the development of technology has given new opportunities to use the thermovision technique in industrial non-destructive testing, which is an important stage in the quality control of foundry ceramic forms. The aim of the work is to determine the influence of the methodology of quality testing of multilayer ceramic forms using active thermovision on the result of these tests and the selection of optimal measurement conditions. As part of the work, a measuring station consisting of a thermal imaging camera was installed together with a computer equipped with image recording software, a ceramic mold rack, an electric air heater and electric infrared heaters. The process of heating up the mold using various heat sources and its influence on the detection of defects was investigated. Recordings from the camera have been developed by computer, with the selection of an optimal color palette that allows to observe the temperature distribution. These studies support the optimization of the industrial use of thermovision technology in non-destructive testing of the quality of ceramic molds used for precise casting of metal elements. Any physical object with a temperature higher than $0 \mathrm{~K}$ emits electromagnetic radiation. The basis of thermovision is the detection by infrared camera of electromagnetic radiation in the infrared band. With the temperature of the object, the length of the electromagnetic waves emitted changes. The thermal imaging camera detects this change and, depending on the temperature and emissivity of the object, the color of the image recorded by the camera changes. In order to obtain accurate results, depending on the type of the examined object, an emissivity factor $(\varepsilon)$ was applied, which should be taken into account using the thermovision method of temperature measurement. The emissivity of popular materials is presented in

Table 1 [1]. 
Table 1 Emissivity table for selected materials [1]

\begin{tabular}{|l|c|c|}
\hline \multicolumn{1}{|c|}{ Material } & Temperature $\left({ }^{\circ} \mathrm{C}\right)$ & Emissivity coefficient (1) \\
\hline Polished aluminum & $50-100$ & $0.04-0.06$ \\
\hline Rough aluminum & $20-50$ & $0.06-0.07$ \\
\hline Zinc sheet & 50 & 0.20 \\
\hline Rolled steel sheet & 50 & 0.56 \\
\hline Gypsum & 20 & $0.8-0.9$ \\
\hline Enamel lacquer & 20 & $0.85-0.95$ \\
\hline Oxidized copper & 50 & $0.6-0.7$ \\
\hline White paper & 20 & $0.7-0.9$ \\
\hline Black matte paper & 20 & 0.94 \\
\hline Pure silver polished & 200 & 0.02 \\
\hline Skin & 30 & 0.98 \\
\hline Water & $0-100$ & $0.95-0.98$ \\
\hline
\end{tabular}

As a reference point for radiation measurements, the body is perfectly black, completely absorbing radiation, regardless of the wavelength, angle of incidence and the temperature of the radiating object. The emissivity coefficient $(\varepsilon)$ of a blackbody is 1 . The emission of blackbody radiation (not its surface) changes with the temperature according to the Stefan-Boltzmann law [2]:

$R=\sigma T^{4}$

where: $\sigma$ is the Stefan-Boltzmann constant equal to $5.67 \cdot 10-8\left(\mathrm{~W} / \mathrm{m}^{2} \mathrm{~K}^{4}\right)$

$\mathrm{T}$ - the temperature $(\mathrm{K})$

The essence of the thermovision test is the display of heat emitted by physical objects in the infrared band (wavelength from 700 to $1400 \mathrm{~nm}$ ). This allows the registration of thermal radiation emitted by physical bodies without the need to illuminate them with an external light source [3]. Thermovision belongs to the group of nondestructive examinations, it means those that do not interfere with the physical structure of the material under investigation. Compared to destructive tests, this is beneficial in many respects and opens up extensive research possibilities for small-lot production items that can not be destroyed at the quality control stage. Thermovision tests enable detection of any abnormalities in which the temperature distribution plays a major role.

\section{METHODOLOGY}

In order to approximate the suitability of active thermovision research, the process of creating ceramic casting molds and defects that may arise during this process should be known. The first stage of the production process of components manufactured by precision casting is the implementation of wax models. Then the prepared models are combined with the fill system into model sets. They are washed, dried, then directed to a line for the production of ceramic molds. The next step is applying ceramic layers to the model sets. It consists in alternating immersion in the ceramic surface layer, covering with ceramic powder and drying. On average, molds are made from 7 to 9 layers. Prepared in this way, he directs himself to burn the wax in a three-zone pusher furnace. At this stage, quality control is carried out by weighing and visual inspection. The next step is to insulate the mold and place the ceramic filter in the mold pan. In this form, the forms are annealed in a threezone pusher furnace at $1200^{\circ} \mathrm{C}$. After cooling, the ceramic mold is ready for the next production step of the cast elements. Materials for making molds are ceramic flour, an aqueous or alcoholic binder and other 
ingredients necessary to obtain the required properties. Ceramic flour is most often based on silica. The binder is most often hydrated sodium silicate or hydrolyzed ethyl silicate. The molds are directed directly to the vacuum furnace where the vacuum is produced and the molds are placed in the furnace infusion chamber. The casting alloy is melted, after which the mold is poured and placed in the vacuum chamber. Then the molds are removed from the furnace so that they can cool down and the casts solidify. After cooling, the insulation is separated and the molds are broken. Each stage of production is burdened with the risk of defects that may cause the product to be unserviceable. They are mainly:

- defects of wax models: graininess, flowing lines, wax model deformation, shrinkage, cracking, flashing, air bubbles, geometrical defect,

- ceramic mold defects: cracking, cracking of the model coat, delamination of the mold, defect of the coating,

- casting defects: penetration of metal and ceramic inclusions, penetration of obsbet, imperfections, exclusion and inclusions, puncture and dissection, bulge, scabs, groats or accretions, discontinuity, porosity, mechanical damage of castings.

Quality control at each stage of production is aimed at eliminating defective components. The most important thing is to capture as many disadvantages as possible before the casting process, as compared to the cost of manufacturing wax models and ceramic forms are relatively low [4].

The tests were performed in laboratory and industrial conditions. Ceramic molds used for casting aircraft engine blades were used for research. To determine their thickness and porosity, measurements were made using active thermovision. In laboratory tests, heat sources in the form of a heater and infrared radiators were used to heat molds. A measurement stand was built for the laboratory tests consisting of: FLIR T640 thermal imaging camera connected to a computer with ResearchIR software installed, frame for mold setting, insulation screen, WELDY Energy HT3400 electric

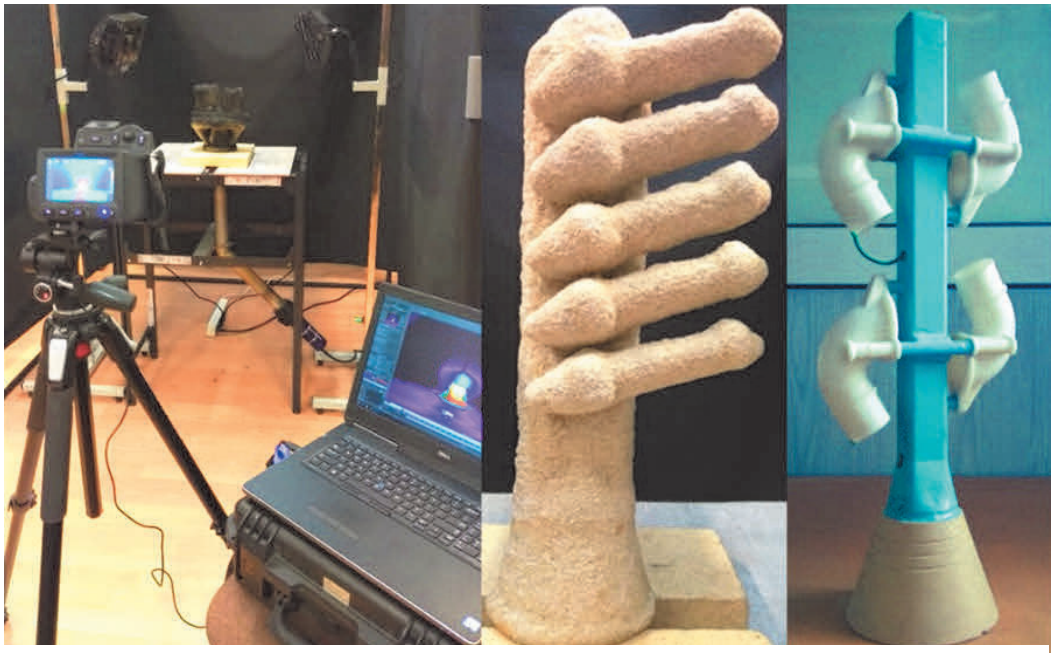

Figure 1 Measuring stand, ceramic form, model set [5] heater, two pieces of infrared heaters. Three tests with different heat sources were carried out in laboratory conditions, the test mold was heated and then cooled down at room temperature. In the first case, infrared radiators were used. In the second case, an electric heater was used, while in the third case, radiators and heater were used. All tests were recorded using a thermal imaging camera, and the obtained thermograms were developed in the Research IR program. Measuring stand, ceramic form, model set is shown in Figure 1.

\section{RESULTS AND DISSCUSION}

In study No. 1 using infrared heaters, the lowest temperatures were obtained, surfaces perpendicular to the direction of infrared radiation were heated. The heating curves are shown in Figure 2. The temperature obtained did not allow to observe the disadvantages of the ceramic mold under study. During the test No. 2 using the electric heater it was possible to achieve higher temperatures than in the case of using infrared heaters, the heating graph is shown in Figure 3. The temperature obtained allowed to observe differences in thickness in particular places of the ceramic mold. The highest and most evenly distributed temperature of the 
mold was obtained in test No. 3 with the use of simultaneously infrared radiators and electric heater. The heating graph is shown in Figure 4.

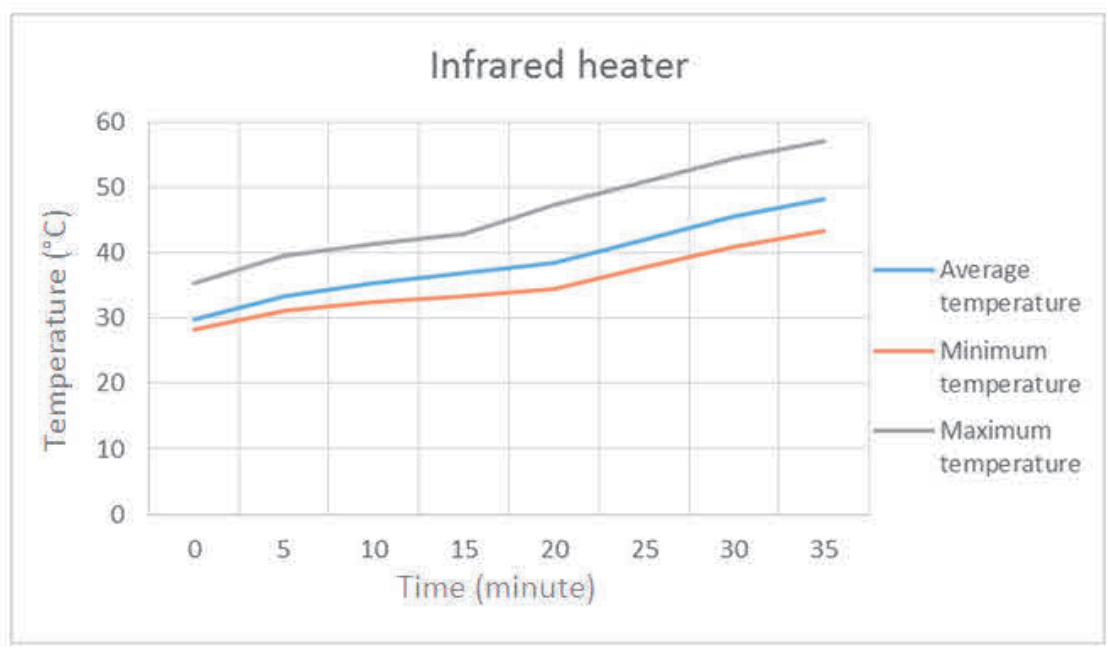

Figure 2 Heating graph of the mold using infrared radiators

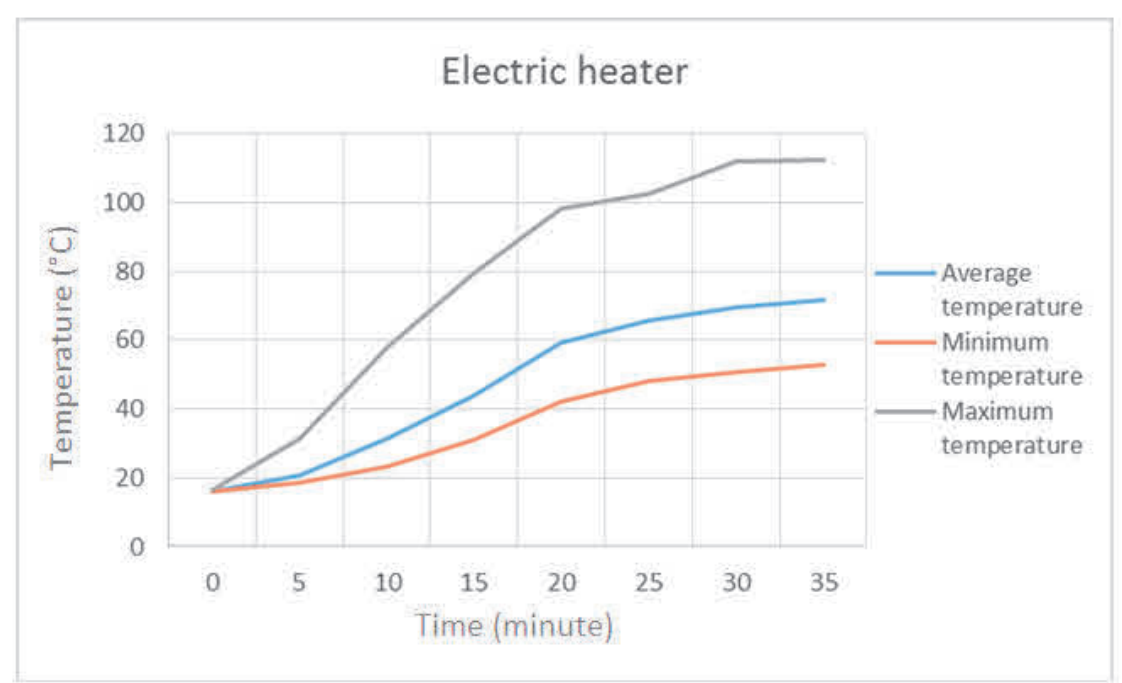

Figure 3 Heating graph of the mold using an electric heater

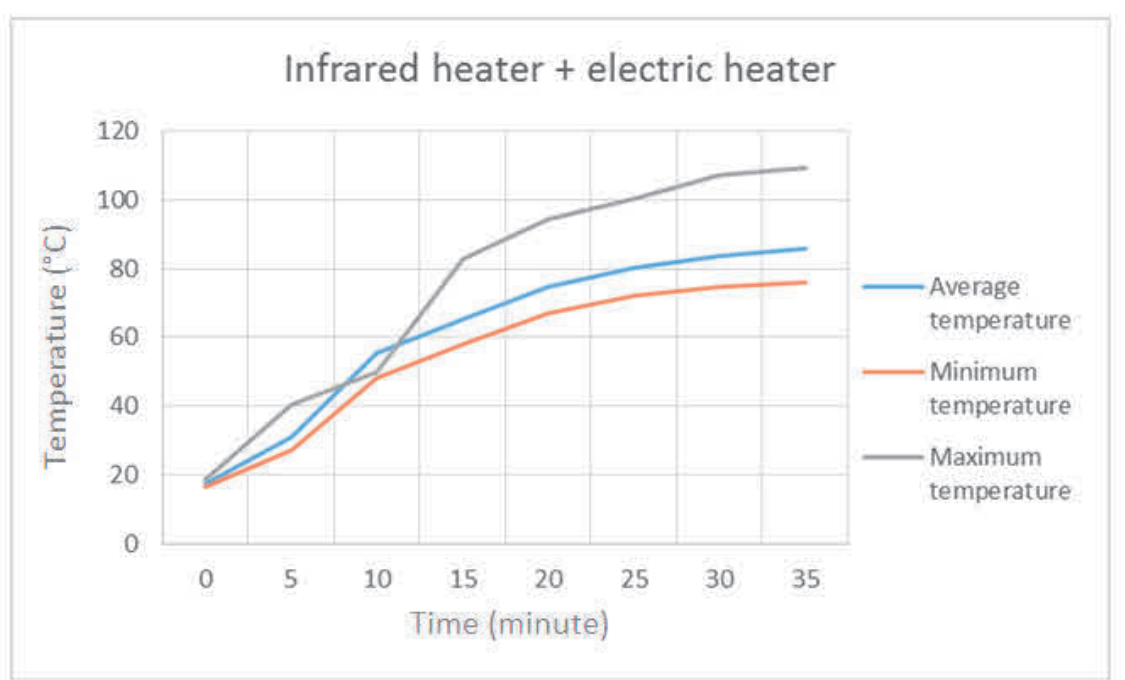

Figure 4 Heating graph of the form using infrared radiators and electric heater 
From the graphs it can be observed that in the case of study No. 1, the difference between the maximum and minimum temperature is small, the test is not reliable. During the tests No. 2 and No. 3, higher temperatures were obtained, and the minimum and maximum temperature differences were large, which indicates differences in the thickness of the individual places of the ceramic mold.

Figure 5 presents thermograms for tests No. 1, No. 2, No. 3. The temperature distribution of the ceramic mold is shown depending on the heat source. Temperature differences of individual mold elements can be observed, depending on its thickness.

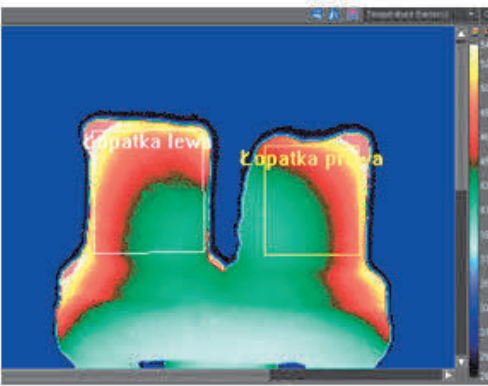

a) study No. 1

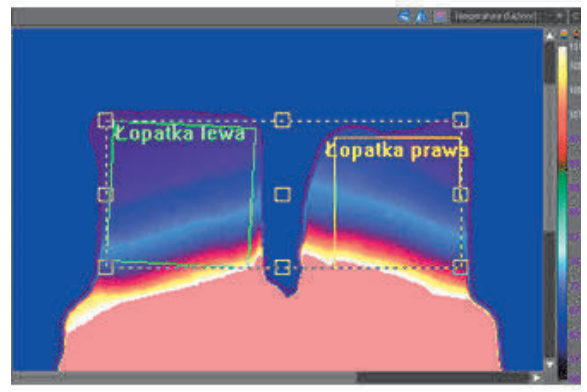

b) study No. 2

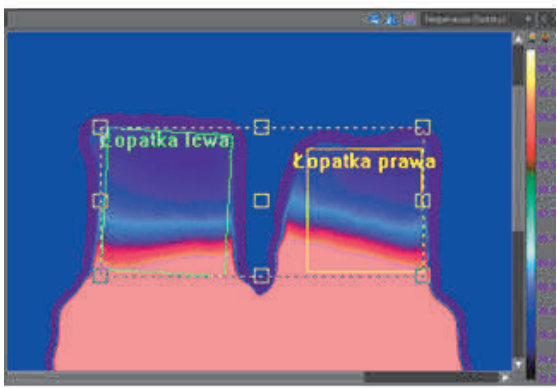

c) study No. 3

Figure 5 Thermograms obtained in study No. 1, No. 2 and No. 3

\section{SUMMARY}

Thermal imaging studies are gaining popularity in industry, mainly due to their non-destructive nature, the ease of measurements and the ever lower prices of measuring instruments. Observation of ceramic forms using thermovision allows detecting defects that may negatively affect the quality of the final product. The performed tests have revealed differences in the thickness of the individual elements of the casting mold, which negatively affects the crystallization conditions of the cast material. It is necessary to choose the optimal source of heat, in the case of the form being tested, it is the simultaneous use of an electric heater and infrared radiators.

\section{ACKNOWLEDGEMENTS}

\section{The work done in the framework of a research project No. PBS3/A5/54/2016 funded by the National Centre for Research and Development}

\section{REFERENCES}

[1] ŻURAWSKI, J. Termowizja jako weryfikacja jakości prac izolacyjnych, Izolacje, 2008. vol. 131, pp. 36-39.

[2] KĄKOL Z., MORAWSKI P. Ciało doskonale czarne, e-podręczniki AGH, Kraków, 2015, [online, viewed 03.04.2019], available from:

https://epodreczniki.open.agh.edu.pl/tiki-index.php?page=Cia\%C5\%820+doskonale+czarne

[3] termowizja.e26.eu; Czym jest termowizja, [online, viewed 03.04.2019], available from: http://www.termowizja.e26.eu/termowizja.php

[4] ŻABA K. Lectures, Materiały i technologie w przemyśle lotniczym i motoryzacyjnym, AGH, Kraków

[5] Centrum Druku 3D; Zastosowanie technik wytwarzania przyrostowego w odlewnictwie, [online, viewed 03.04.2019], available from:

http://centrumdruku3d.pl/zastosowanie-technik-wytwarzania-przyrostowego-w-odlewnictwie/ 